\title{
Three generations under low versus high neighborhood density affect the life history of a clonal plant through differential selection and genetic drift
}

\author{
Mark van Kleunen, Markus Fischer and Bernhard Schmid
}

\begin{abstract}
We tested whether neighborhood density affects the clonal life history of the stoloniferous plant Ranunculus reptans through selection and genetic drift. After three generations of sexual reproduction of 16 low and 16 high density lines, we studied traits related to growth form and reproduction in a common competition free environment. A $7.7 \%$ lower branching frequency and slightly longer internodes indicated an evolutionary shift towards a less compact growth form under high neighborhood density, but because stolons grew also more vertically, horizontal spread per ramet was slightly decreased. Neighborhood density had no directional effects on the evolution of allocation to sexual and vegetative reproduction in $R$. reptans. Variation among replicated high density lines was significantly lower than among replicated low density lines in both growth form and reproductive characteristics, indicating less pronounced genetic drift under high neighborhood density. This study demonstrates that a clonal plant can respond to selection imposed by neighborhood density. Moreover, it shows that the effect of random genetic drift increases with decreasing neighborhood density. In a declining species, such as $R$. reptans in central Europe, this may lower the potential for adaptive evolutionary change and increase extinction risk.
\end{abstract}

M. van Kleunen, M. Fischer and B. Schmid, Inst. of Environmental Sciences, Universität Zürich, Winterthurerstrasse 190, CH 8057 Zurich, Switzerland. Present address for MvK and MF: Inst. für Biochemie und Biologie, Universität Potsdam, Lennéstr. 7a, DE 1447I Potsdam, Germany (vkleunen@rz.uni potsdam.de).

Plant density is likely to affect both the ecological and genetic interactions within the neighborhood area of a plant (Antonovics and Levin 1980), and is thus likely to be an important factor in plant evolution. Theory predicts that density dependent selection affects life histories of unitary organisms in such a way that they show $\mathrm{r}$ selected characteristics at low and $\mathrm{K}$ selected characteristics at high density (MacArthur and Wilson 1967, Pianka 1970). However, it is still unclear how and to which extent the theoretical predictions may also apply for modular organisms with vegetative reproduc tion (Salisbury 1942, Klimeš et al. 1997), which have as a consequence populations and life histories of both ramets and genets (Sackville Hamilton et al. 1987, Schmid 1990, Fischer and van Kleunen 2001).

Here we report results of the first selection experiment under two levels of neighborhood density using genets of a clonal plant species, Ranunculus reptans L. We tested whether density dependent selection imposed by high versus low ramet and correlated genet density in defined neighborhood areas leads to evolutionary changes in life history characters, particularly those of genets. We define genets as sets of ramets derived from single seeds (Harper 1977). We created replicates of an experimental 
population which were allowed to evolve for three genet generations at low and high densities. This could result in genetic differentiation between low and high density lines if the genets that contributed large numbers of seedlings to the following genet generations differed between the density environments.

As a consequence of increased intraspecific competi tion, high neighborhood density may affect the fitness of clonal plants through a reduction in growth and changes in reproductive allocation (Abrahamson 1975, Schmid and Harper 1985, Humphrey and Pyke 1998 , van Kleunen et al. 2001). Under high density, a high allocation to sexual reproduction may allow escape from locally adverse conditions (Ogden 1974, Abrahamson 1975, Loehle 1987), while on the other hand a high allocation to vegetative reproduction may increase competitive strength and result in a higher seed produc tion in the long term (Loehle 1987). In $R$. reptans density causes a plastic increase in the relative allocation to sexual over vegetative reproduction (van Kleunen et al. 2001), but reproductive allocation does not respond to density dependent selection in populations without seed recruitment (van Kleunen and Fischer 2003). It is not known whether the allocation to sexual and vegetative reproduction can show an evolutionary response to selection imposed by density over several sexually reproducing genet generations.

As a consequence of variation in spacer length and branching frequency, clonal growth form may range from compact with highly aggregated ramets to spread ing with more dispersed ramets (so called phalanx and guerilla strategies, respectively; Lovett Doust 1981). Growth form is likely to have important consequences for survival and reproductive output of clonal plants, and thus to be under selection. Therefore, growth form characteristics of clonal plants can be considered as life history traits (Fischer and van Kleunen 2001). The highly spreading guerilla plants may rapidly occupy the space available under low density, whereas the competi tively stronger phalanx plants are more likely to persist under high density (Winkler and Schmid 1995, Winkler et al. 1999). On the other hand, guerilla plants such as $R$. reptans may escape from unfavourable high density patches, whereas a phalanx plant does not have this possibility (Schmid 1986, 1991).

Although experimental studies on evolutionary changes in response to selection are quite frequent, experimental studies on the importance of other evolu tionary forces such as genetic drift on life history characters are surprisingly rare (Rich 1984, Newman and Pilson 1997). Especially in declining species, such as $R$. reptans in central Europe, genetic drift may be detrimental because it lowers the potential for adaptive evolutionary change and increases extinction risk. Therefore, we additionally tested whether neighborhood density may affect evolution of life history characters through effects on random genetic drift. The magnitude of genetic drift is negatively related to the effective population size (Hartl and Clark 1994). Plant density is likely to affect genetic drift due to its influence on effective sizes of both the population and the genetic neighborhood of individual plants within the population (Thomas and Bazzaz 1993, van Kleunen et al. 2001). Although population size is determined by both the genet density of a population and the area covered by the population, for habitat specialists such as $R$. reptans with a restricted available amount of growing area, density is likely to be the main factor. Moreover, if within a population the neighborhood of plants is considered, in which most ecological and genetic inter actions occur (Antonovics and Levin 1980), there are most likely fewer genets in a low density neighborhood than in a high density neighborhood, especially for a guerilla plant with intermingling genets such as $R$. reptans. This leads to the prediction that the magnitude of random genetic drift should be smaller under high than under low neighborhood density.

We studied evolutionary responses of size, reproduc tive allocation, and growth form of genets after three generations of sexual reproduction at low and high ramet density in defined neighborhood areas. Because each generation was started by planting arrays of ramets derived from several genets, genet density at the scale of local neighborhoods varied simultaneously with ramet density between the two treatments. To test our predic tion about genetic drift, we replicated our selection experiment in 16 low and 16 high density lines and analysed the variation in selection response along with the mean selection response.

\section{Material and methods}

\section{Study species}

Ranunculus reptans L. (Ranunculaceae) is a stolonifer ous, rosette forming herb with a circumpolar distribu tion, mainly in the temperate to boreal-subarctic zones of Europe, Asia, and North America (Hess et al. 1980). In central Europe, the species only grows on periodically inundated river and lakeshores with low vegetation cover (Prati 1998). Because of the regulation of water levels of most rivers and lakes, $R$. reptans has become a rare species in central Europe where it is now mainly found around Lake Constance, which borders Austria, Germany and Switzerland. There, it frequently grows in small patches of $<1 \mathrm{~m}^{2}$ area. Such patches of different densities consist of intermingling genets (Fischer et al. 2000b).

Rosettes (i.e. ramets) of $R$. reptans consist of up to 20 leaves. Its leaf blades are $10-50 \mathrm{~mm}$ long and $1-5 \mathrm{~mm}$ wide and gradually narrow into the petioles. Stolon branches are produced from meristems in the axils of 
leaves, and consist of thin $(0.5-2.0 \mathrm{~mm}$ diameter $)$ internodes with a length of $3-5 \mathrm{~cm}$. New ramets are produced at the nodes. Stolon branches can grow $10-20 \mathrm{~cm}$ within one growing season, which may result in high ramet densities. Each ramet has the potential to produce roots and a single flower, and as a consequence vegetative and sexual reproduction are not mutually exclusive in $R$. reptans. The slightly proterandrous flowers of the partially self incompatible $R$. reptans can produce 10-20 seeds (Prati and Peintinger 2000).

\section{Collection and precultivation of plants}

Collection and precultivation of plants was the same as described in van Kleunen et al. (2001) and van Kleunen and Fischer (2003). To comprehensively sample poten tial genetic variation in $R$. reptans, we collected a total of 40 ramets from 10 natural populations around Lake Constance from 1995-1997. RAPD analysis revealed that all 40 ramets represented different genets (Fischer et al. 2000b). Moreover, we found significant variation among these genets in the proportion of flowering and of rooted ramets, leaf length, stolon-internode length and spatial spread per ramet when they were grown in a competition free environment (all $\mathrm{P}<0.05$; $\mathrm{M}$. van Kleunen, unpubl.). The collected genets were propagated repeatedly, and on 8 August 1997, we used ramets of the 40 genets to found one large mixed population divided over thirty two $31 \times 44 \mathrm{~cm}$ trays filled with a $4: 1$ mixture of sand and compost. This population was allowed to reproduce only vegetatively until we had a sufficient number of ramets to start the experiment described below. Both the pre cultivation of plants and the experiment took place in a plant room at $25^{\circ} \mathrm{C}$ with 16 hours of artificial light (ca $300 \mu \mathrm{E} \mathrm{m}^{-2} \mathrm{~s}^{-2}$ ).

\section{Experimental setup}

On 5 March 1998, we excavated all rooted ramets from the mixed population, and randomly assigned them to evenly spaced, hexagonally arranged planting positions in each of thirty two $31 \times 44 \mathrm{~cm}$ trays, simulating neighborhood areas, filled with a soil mixture of the same composition as described above. To create 16 replicates of the mixed population at low density (low density lines) and 16 replicates at high density (high density lines), we planted into 16 trays 40 ramets (293 ramets $\mathrm{m}^{-2}$ ) and into the other 16 trays 200 ramets $\left(1466\right.$ ramets $\mathrm{m}^{-2}$ ). Both densities are within the range of ramet densities observed in the field (M. Fischer, pers. obs.). Because the base population contained 40 genets and ramets were drawn randomly from it, genet density was lower in the low ramet density neighbourhoods than in the high ramet density neighborhoods. As a conse quence of vegetative reproduction, ramet densities increased during the experiment but always remained higher for the high density lines than for the low density lines (van Kleunen et al. 2001, M. van Kleunen, unpubl.). Plants were watered at two day intervals, and trays were randomly assigned to new positions in the plant room at two week intervals.

In order to get seeds to start the next genet generation, we hand pollinated all open flowers within each tray (i.e. within each replicate line) every second or third day. With a pair of tweezers, we took 4-5 anthers from each flower and moved them over the stigmata of 2-3 randomly chosen other flowers. Each flower was thus used both as pollen donor and receptor. Due to this pollination procedure, selection on genets was imposed by the density environment, i.e. at each density, genets with the highest sexual reproductive effort were likely to contribute most offspring to the next genet generation of each line. Between pollinations within different trays, we sterilized the pair of tweezers in a flame. About one month after pollinating a flower, we harvested its seeds and stored them in closed plastic boxes in a refrigerator.

On 14 September 1998, we sowed all seeds on a 1:3 mixture of sand and compost after they had been incubated in a solution of $2 \mathrm{mg} \mathrm{ml}^{-1}$ gibberellic acid for five days to break dormancy. Thirty days later, we planted the seedlings into experimental trays similar to the ones used in the first generation. Because there were fewer than 40 and 200 seedlings for most low and high density lines, respectively, we planted on average 30.8 seedlings for the low density lines (median $=32.5$, range $=9-40)$ and 126.8 seedlings for the high density lines (median $=132.0$, range $=64-165$ ) in the second generation, and repeated the pollination and germina tion procedures. Because of again low seedling numbers, we planted the third generation in trays of half the size of the ones used in the previous generations. To maintain the same densities as in the previous generations, we planted into these smaller trays 20 and 100 seedlings of the low density and high density lines, respectively. Again we repeated the pollination procedure. During the experiment, two high density lines dried out and were lost. Because each selection generation started from seedlings, ramet density always varied simultaneously with genet density.

To test whether clonal life history traits had geneti cally diverged between low and high density lines after three generations of selection, we planted the offspring of the third generation into a common environment. First, to reduce maternal environmental carry over effects in this fourth generation, we precultivated 15 genets (derived from 15 seeds) of each of the remaining 30 lines for 82 days in $9.5 \times 9.5 \times 11 \mathrm{~cm}$ pots filled with the same soil mixture as used in the previous genera tions. On 26 April 2001, we randomly assigned one rooted ramet of each of the 15 genets of each line to the eight planting positions in each of 56 experimental trays 
similar to the ones used in the base generation with the limitation that ramets planted to the same tray belonged to different selection lines. Because some lines had fewer than 15 genets, the total number of genets in the fourth and final generation was 439 instead of 450 .

\section{Measurements}

After eight weeks of growth of the fourth generation in the common environment, we counted the number of ramets, rooted ramets and flowers on each genet as estimates of size, vegetative reproduction, and sexual reproduction, respectively. We calculated the proportions of flowering and rooted ramets by dividing the number of flowers and rooted ramets, respectively, by the total number of ramets. We additionally counted the number of carpels of the oldest flower on the longest stolon branch of each plant because this may trade off with the proportion of flowering ramets (van Kleunen et al. 2002). To quantify growth form, we counted the number of branches per genet, and measured the spatial spread of the genet (i.e. the linear distance between the two most distant ramets of a genet), the length of the longest leaf and the combined length of the four oldest internodes on the longest stolon branch on each genet.

\section{Analyses}

We analysed all variables with analyses of variance using the statistical software SPSS (SPSS Inc., Chicago, Illinois, USA). We considered selection density as a fixed factor and the lines within selection densities as a random factor. Because genetic drift is likely to be smaller under high density than under low density, we expected the variance to be lower among high density lines than among low density lines (Falconer and Mackay 1996). Therefore, the assumption of homosce dasticity was likely to be violated. Therefore, we calculated mean squares separately for the high and low density lines, and tested the density effect conserva tively against the group of lines (i.e. high or low density lines) with the highest mean squares rather than against all lines. To improve normality of residuals we $\log 10$ transformed number of ramets, proportion of rooted ramets, spatial spread per ramet, and number of branches per ramet prior to analyses.

To test whether variation among high density lines was indeed lower than among low density lines, we calculated the variance components among high density and low density lines for each trait and the ratio between them from analyses of variance (Sokal and Rohlf 1995). We tested these ratios with one tailed $F$ tests because of the specific prediction of lower variance among high density lines.

\section{Results \\ Evolutionary responses of genet size and reproduction to neighborhood density}

After three sexual generations, genets of the high density lines had $7.2 \%$ more ramets, a $2.9 \%$ lower proportion of rooted ramets, $0.7 \%$ higher proportion of flowering ramets, and $3.1 \%$ more carpels per flower than plants of the low density lines (Fig. 1a, Table 1). However, these differences were not significant (Table 2a), suggesting that there was no evolutionary response to neighbor hood density for total size and reproductive allocation of genets in $R$. reptans.

\section{Evolutionary responses of genet growth form to neighborhood density}

After three sexual generations, plants of the high density lines had 3.5\% longer leaves, $7.7 \%$ fewer branches per ramet, $2.4 \%$ longer stolon internodes, but a $10 \%$ lower horizontal spread per ramet than plants of the low density lines (Fig. 1b, Table 1). These differences were marginally significant in a multivariate analysis of variance $\left(\mathrm{F}_{4,112}=2.01, \mathrm{P}=0.098\right)$ and individually sig nificant for the number of branches per ramet $(\mathrm{P}=0.013$; Table 2b). Lower branching frequency and longer internodes are consistent with increased guerilla like growth form, although this shift in growth form resulted in a lower rather than higher horizontal spread per ramet. This was due to stolons, which, like the leaves, escaped from neighborhood density by elongating verti cally as well as horizontally (M. van Kleunen, pers. obs.).

\section{Effects of neighborhood density on variation among selection lines}

Compared to the directional effects of neighborhood density on average selection responses, density effects on the variation among lines were more pronounced. There was significant variation among lines in the proportion of flowering ramets, the number of carpels per flower, leaf and internode lengths, and marginally significant variation in the spatial spread per ramet (Table 2). The variation was lower among high density than among low density lines for the number of ramets, the propor tions of flowering ( $\mathrm{P}<0.001$, Fig. 1, Table 3$)$ and of rooted ramets $(\mathrm{P}=0.033)$, the number of carpels per flower (not significant, $\mathrm{P}=0.185$ ), and the spatial spread per ramet $(\mathrm{P}=0.007)$. Only for internode length the variation was higher among high than among low density lines (Table $3 ; F_{13,15}=9.43$, two tailed $\mathrm{P}<0.001$ ). For the numbers of ramets and of branches per ramet, $F$ ratios could not be calculated based on variance components because they were zero (negative) 


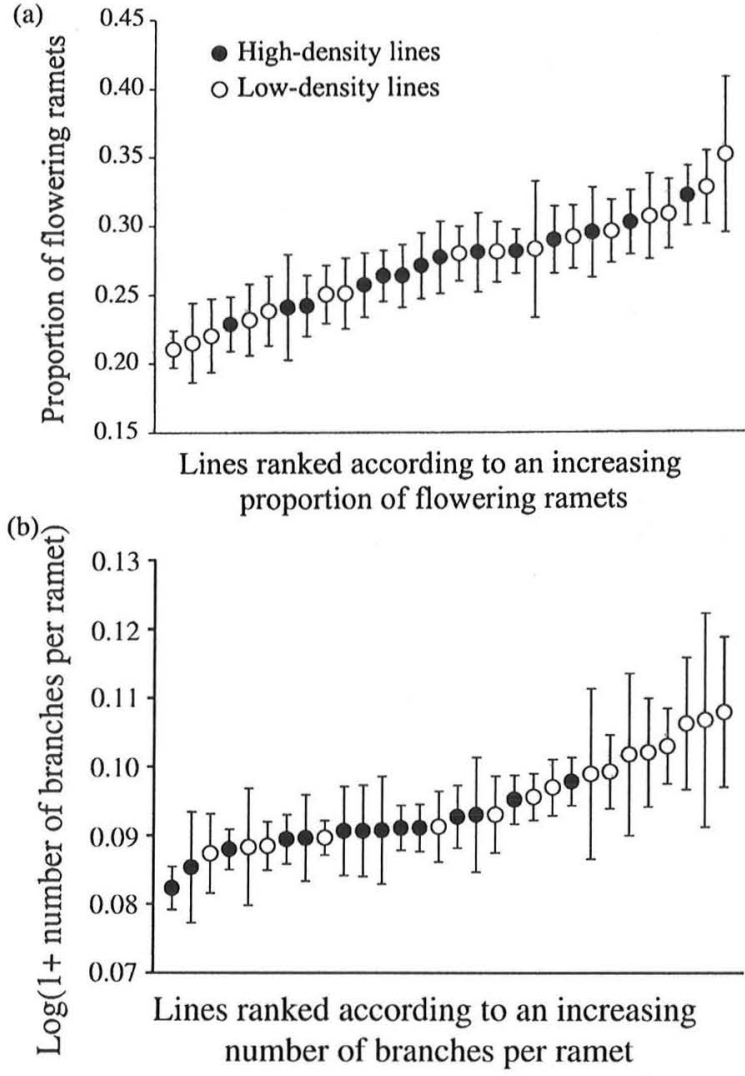

Fig. 1. Means ( $\pm 1 \mathrm{SE})$ of (a) the proportion of flowering ramets, and (b) the number of branches per ramet for 16 low density (open symbols) and 14 high density lines (filled symbols) of Ranunculus reptans at the end of a three generation selection experiment. In both graphs, lines were ranked according to their mean values. Variation in the proportion of flowering ramets was significantly higher among low density lines than among high density lines $(\mathrm{P}<0.001$ Table 3), and the number of branches per ramet was signifi cantly higher for low density lines than for high density lines $(\mathrm{P}=0.013$; Table 2b).

among high density lines (Table 3 ). The overall lower variation among high density lines than among low density lines is consistent with our prediction that random genetic drift becomes a stronger evolutio nary force with decreasing neighborhood density in $R$. reptans.

\section{Discussion}

\section{Adaptive evolutionary responses to selection imposed by neighborhood density}

Clonal growth and vegetative reproduction are impor tant for the maintenance of populations of many plants. However, for these characters to evolve rapidly there must be genetic variation among genets and recombina tion via sexual reproduction (Sackville Hamilton et al. 1987). Although density dependent selection using only vegetatively produced offspring may result in evolution ary changes as shown in a previous study (van Kleunen and Fischer 2003), it has to rely exclusively on changes in the frequency of the original genotypes or on somatic mutations and perhaps epigenetic changes. In the current selection experiments, we therefore started subsequent generations of the selection lines from sexually produced seeds. Between the time from seed germination to seed production genets could show differential clonal growth, ramet mortality, ovule and pollen production, and fertilization success, which can all contribute to life history evolution.

After three generations, low and high density lines had not diverged for the number of ramets, proportions of rooted and of flowering ramets, and number of carpels per flower, even though there was significant heritable variation in the base population for these measures of genet size and reproduction (Prati and Schmid 2000, van Kleunen et al. 2000a, b, van Kleunen and Fischer 2001). Moreover, in another experiment in which we directly selected on the proportion of flowering ramets, the selected trait responded significantly within two generations (van Kleunen et al. 2002). Therefore, the present results indicate that the different components of reproduction are either selectively neutral to density or

Table 1. The mean evolutionary effect of low and high density on reproduction and growth form of Ranunculus reptans at the end of a three generation selection experiment. Plants of the fourth generation were grown in a common environment. Means are given $\pm 1 \mathrm{SE}$ for non transformed data, and \pm upper SE/lower SE for $\log 10$ - transformed data after back transformation. The difference between the low and high density lines was significant for the number of branches per ramet $(\mathrm{P}=0.013$; Table $2 \mathrm{~b})$.

\begin{tabular}{lcc}
\hline Trait & Low density lines & High density lines \\
\hline Reproduction & & $49.0 \pm 2.4 / 2.3$ \\
$\quad$ number of ramets & $45.7 \pm 3.0 / 2.8$ & $0.192 \pm 0.008 / 0.008$ \\
proportion of rooted ramets & $0.198 \pm 0.008 / 0.008$ & $0.273 \pm 0.007$ \\
proportion of flowering ramets & $0.271 \pm 0.010$ & $16.6 \pm 0.4$ \\
$\quad$ number of carpels per flower & $16.1 \pm 0.4$ & $5.52 \pm 0.30 / 0.29$ \\
Growth form & $6.13 \pm 0.37 / 0.35$ & $0.232 \pm 0.003 / 0.003$ \\
spatial spread per ramet (mm) & $0.251 \pm 0.005 / 0.005$ & $58.1 \pm 1.4$ \\
number of branches per ramet & $56.2 \pm 1.2$ & $183.1 \pm 4.0$ \\
length of longest leaf (mm) & $178.7 \pm 2.3$ & \\
length of oldest four stolon internodes (mm) & & \\
\hline
\end{tabular}


Table 2. Summary of analyses of variance of evolutionary effects of low and high density and of variation among lines at the end of a three generation selection experiment on (A) reproduction and (B) growth form of Ranunculus reptans. The number of ramets, the proportion of rooted ramets, the spatial spread per ramet, and the number of branches per ramet were $\log$ transformed prior to analyses. Because we expected inequality in variance between the low and high density lines, we tested the selection density effect conservatively against the group of lines (i.e. low or high density lines) with the largest mean squares (MS).

\begin{tabular}{|c|c|c|c|c|c|c|c|c|c|c|c|c|c|}
\hline \multirow{2}{*}{$\begin{array}{l}\text { A } \\
\text { Effect }\end{array}$} & \multirow[t]{2}{*}{ df } & \multicolumn{3}{|c|}{ Number of ramets } & \multicolumn{3}{|c|}{ Proportion of rooted ramets } & \multicolumn{3}{|c|}{ Proportion of flowering ramets } & \multicolumn{3}{|c|}{ Number of carpels per flower* } \\
\hline & & MS & $\mathrm{F}$ & $\mathrm{P}$ & MS & $\mathrm{F}$ & $\mathrm{P}$ & MS & $\mathrm{F}$ & $P$ & MS & $\mathrm{F}$ & $\mathrm{P}$ \\
\hline $\begin{array}{l}\text { Density } \\
\text { Line(density) } \\
\text { low density lines } \\
\text { high density lines } \\
\text { Residual } \\
\text { low density lines residual } \\
\text { high density lines residual }\end{array}$ & $\begin{array}{r}1 \\
28 \\
15 \\
13 \\
400 \\
215 \\
185\end{array}$ & $\begin{array}{l}0.08478 \\
0.12900 \\
0.16600 \\
0.08555 \\
0.12700 \\
0.12200 \\
0.13300\end{array}$ & $\begin{array}{l}0.51 \\
1.02 \\
1.36 \\
0.64\end{array}$ & $\begin{array}{l}0.486 \\
0.440 \\
0.169 \\
0.818\end{array}$ & $\begin{array}{l}0.000661 \\
0.001843 \\
0.001956 \\
0.001713 \\
0.001386 \\
0.001300 \\
0.001487\end{array}$ & $\begin{array}{l}0.34 \\
1.33 \\
1.50 \\
1.15\end{array}$ & $\begin{array}{l}0.568 \\
0.125 \\
0.107 \\
0.320\end{array}$ & $\begin{array}{l}0.00022 \\
0.01818 \\
0.02578 \\
0.00940 \\
0.01062 \\
0.01194 \\
0.00909\end{array}$ & $\begin{array}{l}0.01 \\
1.71 \\
2.16 \\
1.03\end{array}$ & $\begin{array}{l}0.922 \\
0.015 \\
0.009 \\
0.424\end{array}$ & $\begin{array}{l}32.205 \\
26.272 \\
27.506 \\
24.848 \\
13.697 \\
12.074 \\
15.570\end{array}$ & $\begin{array}{l}1.17 \\
1.92 \\
2.28 \\
1.60\end{array}$ & $\begin{array}{l}0.296 \\
0.004 \\
0.005 \\
0.089\end{array}$ \\
\hline B & $\mathrm{df}$ & Spatial & ead pe & met $^{\AA}$ & Number o & anches & er ramet & Len & of lon & t leaf & Length 0 & $\begin{array}{l}\text { dest fo } \\
\text { rnodes }\end{array}$ & stolon \\
\hline Effect & & MS & $\mathrm{F}$ & $P$ & MS & $\mathrm{F}$ & $P$ & MS & $\mathrm{F}$ & $P$ & MS & $\mathrm{F}$ & $P$ \\
\hline $\begin{array}{l}\text { Density } \\
\text { Line(density) } \\
\text { low density lines } \\
\text { high density lines } \\
\text { Residual } \\
\text { low density lines residual } \\
\text { high density lines residual }\end{array}$ & $\begin{array}{r}1 \\
28 \\
15 \\
13 \\
400 \\
215 \\
185\end{array}$ & $\begin{array}{l}0.1250 \\
0.0871 \\
0.1020 \\
0.0703 \\
0.0611 \\
0.0615 \\
0.0606\end{array}$ & $\begin{array}{l}1.23 \\
1.43 \\
1.66 \\
1.16\end{array}$ & $\begin{array}{l}0.285 \\
0.075 \\
0.061 \\
0.313\end{array}$ & $\begin{array}{l}0.005588 \\
0.000466 \\
0.000700 \\
0.000195 \\
0.000754 \\
0.001016 \\
0.000449\end{array}$ & $\begin{array}{l}7.98 \\
0.62 \\
0.69 \\
0.43\end{array}$ & $\begin{array}{l}0.013 \\
0.937 \\
0.793 \\
0.957\end{array}$ & $\begin{array}{l}346.436 \\
344.631 \\
327.309 \\
364.617 \\
139.339 \\
126.254 \\
154.546\end{array}$ & $\begin{array}{l}0.95 \\
2.47 \\
2.59 \\
2.36\end{array}$ & $\begin{array}{r}0.348 \\
<0.001 \\
0.001 \\
0.006\end{array}$ & $\begin{array}{l}2280.08 \\
2039.68 \\
1246.65 \\
2954.72 \\
1071.87 \\
1045.02 \\
1103.46\end{array}$ & $\begin{array}{l}0.77 \\
1.90 \\
1.19 \\
2.68\end{array}$ & $\begin{array}{l}0.396 \\
0.004 \\
0.281 \\
0.002\end{array}$ \\
\hline
\end{tabular}

* For the number of carpels per flower, the df of residual, low density lines residual and high density lines residual are 362, 194 and 168, respectively.

A For the spatial spread per ramet, the df of residual, low density lines residual and high density lines residual are 386, 207 and 179, respectively.

${ }^{1}$ For the length of oldest four internodes, the df of residual, low density lines residual and high density lines residual are 394, 213 and 181, respectively. 
Table 3. Summary of analyses of inequality of variance in reproduction and growth form between the 16 low density and 14 high density lines of Ranunculus reptans at the end of a three generation selection experiment. Plants of the fourth generation were grown in a common environment. The number of ramets, the proportion of rooted ramets, the spatial spread per ramet, and the number of branches per ramet were $\log 10$ transformed prior to analyses. Differences between variation among low density lines and among high density lines were tested with one tailed $\mathrm{F}$ tests of the ratio between the variance among low density lines and among high density lines. For the number of ramets and the number of branches per ramet, we found negative variance components (which were set to zero) and as a consequence we could not calculate $F$ values for these traits.

\begin{tabular}{|c|c|c|c|c|}
\hline Trait & $\begin{array}{l}\text { Variance among } \\
\text { low density lines }\end{array}$ & $\begin{array}{l}\text { Variance among } \\
\text { high density lines }\end{array}$ & $F_{15,13}$ & $\mathrm{P}$ \\
\hline \multicolumn{5}{|l|}{ Reproduction } \\
\hline number of ramets & $3.051 \cdot 10^{-3}$ & 0 & - & - \\
\hline proportion of flowering ramets & $9.601 \cdot 10^{-4}$ & $2.218 \cdot 10^{-5}$ & 43.29 & $<0.001$ \\
\hline proportion of rooted ramets & $4.552 \cdot 10^{-5}$ & $1.591 \cdot 10^{-5}$ & 2.86 & 0.033 \\
\hline number of carpels per flower & 1.178 & 0.715 & 1.65 & 0.185 \\
\hline \multicolumn{5}{|l|}{ Growth form } \\
\hline spatial spread per ramet & $2.890 \cdot 10^{-3}$ & $7.033 \cdot 10^{-4}$ & 4.11 & 0.007 \\
\hline number of branches per ramet & 0 & 0 & - & - \\
\hline length of longest leaf & 13.946 & 14.791 & 0.94 & 0.550 \\
\hline length of oldest four stolon internodes & 14.109 & 133.027 & 0.11 & 1.000 \\
\hline
\end{tabular}

that adaptive evolution is constrained by genetic correla tions among traits. We favour the first explanation because it is in accordance with a simulation study of Sackville Hamilton et al. (1987), who showed that, for non overlapping generations of guerilla species such as $R$. reptans, selection on sexual reproductive allocation does not differ between high and low density environ ments. In another density dependent selection experi ment in which populations of $R$. reptans reproduced exclusively vegetatively for four generations, there was also no response in reproductive allocation (van Kleunen and Fischer 2003).

Genets of our high density lines showed a shift towards a more guerilla like growth form of lower branching frequency and longer internodes (Sutherland and Stillman 1988, Stoll et al. 1998) compared with genets of the low density lines. However, this shift did not lead to increased horizontal spread because the internodes were not growing purely horizontally to escape density stress but also grew more erect. Higher vertical growth may allow the genets to capture more light when grown under competition (van Kleunen and Fischer 2001), and may thus be more beneficial than horizontal growth. Genets of high density lines also showed a tendency to evolve longer leaves, which was also found in another experiment with density depen dent selection in which populations of $R$. reptans reproduced exclusively vegetatively (van Kleunen and Fischer 2003). This can be seen as a further adaptive response to shading when grown under high density because the light gradient is more predictable in the vertical plane (Huber et al. 1998).

Despite an extensive literature on density dependent selection, experimental studies on evolutionary re sponses to density are, surprisingly, very scarce, and the few existing ones are biased towards animals and species with short generation times such as Drosophila melanogaster (Mueller et al. 1991, Joshi et al. 1998).
In these studies, significant evolutionary responses to density dependent selection were generally found and depended on the particular life history of the organism (Mueller 1997). Artificial selection experiments on organisms with longer generation times, such as most plants, show that evolutionary responses can be observed already after a few generations (Mazer et al. 1999, Marek et al. 2000, van Kleunen et al. 2002). In these studies, however, selection was not exerted by different environments but directly by the scientists themselves and therefore relatively strong. In another study on evolutionary responses to selection exerted by low and high density, Law (1979) found that populations of the annual grass Poa апnиa selected for 21 months at high density had a slightly but significantly longer prereproductive period than plants selected at low density. This confirms our finding that evolutionary responses can be observed already after a few generations of selection by different densities.

\section{Effect of neighborhood density on genetic drift}

In clonal plants, it is the number of genets that is relevant for effective population size. Although genet number is related to ramet number, the latter can be considerably higher because of vegetative reproduction of genetically identical ramets by genets. Therefore, effective popula tion size has been theoretically predicted to be generally smaller in clonal than in non clonal plants (Orive 1993). In our experiment, ramet and genet density varied simultaneously (Materials and methods). Consistent with our hypothesis of more pronounced effects of random genetic drift at low than at high neighborhood density, we found larger variation among replicate low density lines than among replicate high density lines for most traits (Table 3). Another possible explanation for 
larger variation among low density lines could be that under low neighborhood density, selection has been weaker than under high density. However, there are no reasons to expect different strength of stabilizing selec tion between low and high density environments, and the only trait for which the outcome of directional selection differed between low and high density treatments (i.e. number of branches per ramet) did not differ in variation among replicate lines between the density treatments. Therefore, we conclude that the generally higher among line variation for low density lines is caused by more pronounced genetic drift rather than by weaker selection.

Another effect that increases the difference in effective population sizes between high and low density popula tions in clonal plants even more can result from a difference in the mode of competition between genets of clonal plants as compared with nonclonal plants. Whereas in nonclonal plants intraspecific competition is generally asymmetric, leading to increased size varia tion (Weiner and Thomas 1986, Weiner 1988), in horizontally spreading clonal plants it is likely to be symmetric (de Kroon et al. 1992, Hara 1994), which can lead to lower size variation under high density as previously observed in $R$. reptans (van Kleunen et al. 2001). Thus, because lower variation in genet sizes increases the effective population size (Hartl and Clark 1994), high density populations of $R$. reptans have even disproportionately larger effective population sizes than low density populations predicted only from the density differences. This results in an even stronger increase in the importance of random genetic drift with decreasing density.

\section{Conclusions}

We conclude, that density can impose directional selec tion on the life history evolution of a clonal plant such as $R$. reptans, and that density effects on random genetic drift as an evolutionary force can be even more pronounced, and certainly have been less often consid ered so far.

Possibly, in a declining species, such as $R$. reptans in Central Europe, more pronounced genetic drift due to low density lowers the potential for adaptive evolution ary change and increases extinction risk, at least in the smallest populations (Fischer et al. 2000a). In an invading species, on the other hand, this may possibly lead to pronounced genetic variation between neighbor hoods and populations, which could then lead to more rapid evolutionary change once these groups coalesce.

Acknowledgements - We thank Rahel Schmid, Gillian Rutherford Rauh, Andrea Lienert, Claudia Pfister, Rebecca Gopfert, Kati Drager, Mirjam Friedli, Franz Fritsche, Philipp
Kocyan, Lukas Wotruba and Thomas Pfluger for practica assistance. We acknowledge financial support by the Swiss National Science Foundation (Grant 31 49728.96).

\section{References}

Abrahamson, W. G. 1975. Reproductive strategies in dewber ries. - Ecology 56: 721-726.

Antonovics, J. and Levin, D. A. 1980. The ecological and genetic consequences of density dependent regulation in plants. - Annu. Rev. Ecol. Syst. 11: 411-452.

de Kroon, H., Hara, T. and Kwant, R. 1992. Size hierarchies of shoots and clones in clonal herb monocultures: do clonal and nonclonal plants compete differently? - Oikos 63: $410-419$.

Falconer, D. S and Mackay, T. F. C. 1996. Introduction to quantitative genetics. - Longman.

Fischer, M. and van Kleunen, M. 2001. On the evolution of clonal plant life histories. - Evol. Ecol. 15: 565-582.

Fischer, M., van Kleunen, M. and Schmid, B. 2000a. Genetic Allee effects on performance, plasticity, and developmental stability in a clonal plant. - Ecol. Lett. 3: 530-539.

Fischer, M., Husi, R., Prati, D. et al. 2000b. RAPD variation among and within small and large populations of the rare clonal plant Ranunculus reptans (Ranunculaceae). - Am. J. Bot. 87: 1128-1137.

Hara, T. 1994. Growth and competition in clonal plants - persistence of shoot populations and species diversity. - Folia Geobot. Phytotax. 29: 181-201.

Harper, J. L. 1977. The population biology of plants. - Academic Press.

Hartl, D. L. and Clark, A. G. 1994. Principles of population genetics. - Sinauer.

Hess, H. E., Landolt, E. and Hirzel, R. 1980. Flora der Schweiz. Vol. 2. - Birkhauser.

Huber, H., Fijan, A. and During, H. J. 1998. A comparative study on spacer plasticity in erect and stoloniferous herbs. - Oikos 81: 576-586.

Humphrey, L. D. and Pyke, D. A. 1998. Demographic and growth responses of a guerrilla and a phalanx perennial grass in competitive mixtures. - J. Ecol. 86: 854-865.

Joshi, A., Wu, W. and Mueller, L. D. 1998. Density dependent natural selection in Drosophila: adaptation to adult crowd ing. - Evol. Ecol. 12: 363-376.

Klimeš, L., Klimešová, J., Hendriks, R. et al. 1997. Clonal plant architecture: a comparative analysis of form and function. - In: de Kroon, H. and van Groenendael, J. (eds), The ecology and evolution of clonal plants. Backhuys Publishers, pp. $1-29$.

Law, R. 1979. Ecological determinants in the evolution of life histories. - In: Anderson, R. M., Turner, B. D. and Taylor L. R. (eds), Population dynamics. Blackwell Scientific Publications, pp. 81-103.

Loehle, C. 1987. Partitioning of reproductive effort in clonal plants: a benefit-cost model. - Oikos 49: 199-208.

Lovett Doust, L. 1981. Population dynamics and local specia lization in a clonal perennial (Ranunculus repens). I. The dynamics of ramets in contrasting habitats. - J. Ecol. 69: $743-755$.

MacArthur, R. H. and Wilson, E. O. 1967. The theory of island biogeography. Monographs in population biology 1 . - Princeton Univ. Press.

Marek, H. B., Biere, A. and van Damme, J. M. M. 2000. Direct and correlated responses to selection on iridoid glycosides in Plantago lanceolata. - J. Evol. Biol. 13: 985-996.

Mazer, S. J., Delesalle, V. A. and Neal, P. R. 1999. Responses of floral traits to selection on primary sexual investment in Spergularia marina: the battle between the sexes. - Evolution 53: 717-731. 
Mueller, L. D. 1997. Theoretical and empirical examination of density dependent selection. - Annu. Rev. Ecol. Syst. 28: 269-288.

Mueller, L. D., Guo, P. Z. and Ayala, F. J. 1991. Density dependent natural selection and trade offs in life history traits. - Science 253: 433-435.

Newman, D. and Pilson, D. 1997. Increased probability of extinction due to decreased genetic effective population size: experimental populations of Clarkia pulchella. - Evolution 51: $354-362$

Ogden, J. 1974. The reproductive strategy of higher plants: II the reproductive strategy of Tussilago farfara L. - J. Ecol. 62: $291-324$

Orive, M. E. 1993. Effective population size in organisms with complex life histories. - Theor. Pop. Biol. 44: 316-340.

Pianka, E. R. 1970. On $\mathrm{r}$ and K selection. - Am. Nat. 104: 592-597.

Prati, D. 1998. The genetics and life history evolution of the clonal plant Ranunculus reptans. - PhD thesis. Univ. of Zurich.

Prati, D. and Peintinger, M. 2000. Biological flora of central Europe: Ranunculus reptans L. - Flora 195: 135-145.

Prati, D. and Schmid, B. 2000. Genetic differentiation of life history traits within populations of the clonal plant Ranun culus reptans. - Oikos 90: 442-456.

Rich, S. S. 1984. An experimental study of genetic drift for two quantitative traits in Tribolium. - J. Hered. 75: 191-195.

Sackville Hamilton, N. R., Schmid, B. and Harper, J. L. 1987. Life history concepts and the population biology of clonal organisms. - Proc. R. Soc. Lond. 232: 35-57.

Salisbury, E. J. 1942. The reproductive capacity of plants: studies in quantitative biology. - Bell and Sons.

Schmid, B. 1986. Spatial dynamics and integration within clones of grassland perennials with different growth form. - Proc. R. Soc. Lond. 228: 173-186.

Schmid, B. 1990. Some ecological and evolutionary conse quences of modular organization and clonal growth in plants. - Evol. Trends Plants 4: 25-34.

Schmid, B. 1991. Konkurrenz bei Pflanzen. - In: Schmid, B. and Stocklin, J. (eds), Populationsbiologie der Pflanzen. Birkhauser, pp. 201-210.

Schmid, B. and Harper, J. L. 1985. Clonal growth in grassland perennials. I. Density and pattern dependent competition between plants with different growth forms. - J. Ecol. 73: $793-808$.
Sokal, R. R. and Rohlf, F. J. 1995. Biometry: the princi ples and practice of statistics in biological research, 3rd ed. - Freeman.

Stoll, P., Egli, P. and Schmid, B. 1998. Plant foraging and rhizome growth patterns of Solidago altissima L. in response to mowing and fertilizer application. - J. Ecol. 86 $341-354$.

Sutherland, W. J. and Stillman, R. A. 1988. The foraging tactics of plants. - Oikos 52: 239-244.

Thomas, S. C. and Bazzaz, F. A. 1993. Some ecological and evolutionary consequences of modular organization and clonal growth in plants. - Ecol. Monogr. 63: 231-249.

van Kleunen, M and Fischer, M. 2001. Adaptive evolution of plastic foraging responses in a clonal plant. - Ecology 82: 3309-3319

van Kleunen, M. and Fischer, M. 2003. Effects of four generations of density dependent selection on life history traits and their plasticity in a clonally propagated plant - J. Evol. Biol. 16: 474-484.

van Kleunen, M., Fischer, M. and Schmid, B. 2000a. Clonal integration in Ranunculus reptans: by product or adapta tion? - J. Evol. Biol. 13: 237-248.

van Kleunen, M., Fischer, M. and Schmid, B. 2000b. Costs of plasticity in foraging characteristics of the clonal plant Ranunculus reptans. - Evolution 54: 1947-1955.

van Kleunen, M., Fischer, M. and Schmid, B. 2001. Effects of intraspecific competition on size variation and reproductive allocation in a clonal plant. - Oikos 94: 515-524.

van Kleunen, M., Fischer, M. and Schmid, B. 2002. Experi mental life history evolution: selection on the allocation to sexual reproduction and its plasticity in a clonal plant - Evolution 56: 2168-2177.

Weiner, J. 1988. The influence of competition on plant reproduction. - In: Lovett Doust, J. and Lovett Doust, L. (eds), Plant reproductive ecology. Oxford Univ. Press, pp $228-245$.

Weiner, J. and Thomas, S. C. 1986. Size variability and competition in plant monocultures. - Oikos 47: 211-222.

Winkler, E. and Schmid, B. 1995. Clonal strategies of herbac eous plant species: a simulation study on population growth and competition. - Abstr. Bot. 19: 17-28.

Winkler, E., Fischer, M. and Schmid, B. 1999. Modelling the competitiveness of clonal plants by complementary analy tical and simulation approaches. - Oikos 85: 217-233. 